\title{
Occupational choice: the market for primary school teachers
}

Citation for published version (APA):

Borghans, L. (1991). Occupational choice: the market for primary school teachers. Researchcentrum voor Onderwijs en Arbeidsmarkt, Faculteit der Economische Wetenschappen. ROA Research Memoranda No. 3E https://doi.org/10.26481/umaror.199103E

Document status and date:

Published: 01/01/1991

DOI:

10.26481/umaror.199103E

Document Version:

Publisher's PDF, also known as Version of record

\section{Please check the document version of this publication:}

- A submitted manuscript is the version of the article upon submission and before peer-review. There can be important differences between the submitted version and the official published version of record.

People interested in the research are advised to contact the author for the final version of the publication, or visit the DOI to the publisher's website.

- The final author version and the galley proof are versions of the publication after peer review.

- The final published version features the final layout of the paper including the volume, issue and page numbers.

Link to publication

\footnotetext{
General rights rights.

- You may freely distribute the URL identifying the publication in the public portal. please follow below link for the End User Agreement:

www.umlib.nl/taverne-license

Take down policy

If you believe that this document breaches copyright please contact us at:

repository@maastrichtuniversity.nl

providing details and we will investigate your claim.
}

Copyright and moral rights for the publications made accessible in the public portal are retained by the authors and/or other copyright owners and it is a condition of accessing publications that users recognise and abide by the legal requirements associated with these

- Users may download and print one copy of any publication from the public portal for the purpose of private study or research.

- You may not further distribute the material or use it for any profit-making activity or commercial gain

If the publication is distributed under the terms of Article $25 \mathrm{fa}$ of the Dutch Copyright Act, indicated by the "Taverne" license above, 
OCCUPATIONAL CHOICE: THE MARKET FOR

PRIMARY SCHOOL TEACHERS

ROA-RM-1991/3E

L. Borghans

RESEARCH CENTRE FOR EDUCATION AND LABOUR MARKET

Faculty of Economic Sciences

Rijksuniversiteit Limburg

Maastricht, May 1991 
CONTENTS

ABSTRACT

1. INTRODUCTION

2. COBWEB THEORY

3. RATIONAL EXPECTATIONS THEORY

4. PREDICTABILITY AND VARIABILITY

5. THE MARKET FOR PRIMARY SCHOOL TEACHERS

6. ENROLMENT WITH EXOGENOUS POLICY

7. ENROLMENT WITH ENDOGENOUS POLICY

8. CONCLUSIONS

APPENDIX: THE DATA

REFERENCES 


\section{ABSTRACT}

The Dutch market for primary school teachers frequently has to contend with mismatches. Shortages and surpluses occur in quick succession. In this respect, reference has many times been made to the cobweb-phenomenon. In this paper the enrolment of students at the teachertraining is studied. The question is to what extent students anticipate future developments at the labour market. Myopic expectations are treated as alternatives for students who are only able to produce low quality forecasts. This implies that in a market with a low variability, students can stick to their myopic expectations better, than use their forecasts. On the other hand, in a market with a large variability or in a situation in which the future is more predictable, it becomes useful to base the enrolment decision on real forecasts.

The demand for teachers is split up into three components. Demand caused by demographic factors has a low variability, but is also relatively well predictable. Replacement demand and the policy component of demand show much more variation and are also less predictable. Therefore, this policy component and replacement demand seem to be the most important causes of the labour market mismatch problems, while demographic changes are relatively unimportant.

An attempt to explain the policy component of demand as a reaction to mismatches failed, which seems to imply that policy is not used to a large extent to adjust for surpluses or shortages at the market.

I would like to thank Hans Heijke, Andries de Grip and Paul Ghijsen for their helpful comments, and Moniek Mols for correcting the English. 


\section{INTRODUCTION}

The choice for education is plagued with uncertainty and, as a consequence, misinvestments. Especially in vocational training, students have to make decisions which imply a specialisation for a certain job and thereby a reduction of other possibilities, at a moment when they can not overlook all the consequences. At the time students commit themselves for a very long period to a certain occupation (or class of occupations) by choosing a vocational training, they are not certain about the demand for that occupation in the relevant future.

In the Netherlands one of the most famous examples of vocational training which has alternately to contend with shortages and surpluses is the training for primary school teachers. While recently there was a large surplus, at present the Forecast Committee for Primary Education predicts shortages in the near future ${ }^{1}$. Mostly, these mismatches are explained by reference to certain incidents, such as changes in payment, an educational reorganisation or e.g. the introduction of mathematics as an entry-requirement. Furthermore, the problems at this market are often explained by the well-known cobweb phenomenon. These explanations have, however, never been investigated systematically.

The aim of this paper is to provide a useful theoretical framework to investigate the market for primary school teachers and to estimate to what extent several sources of uncertainty contribute to the mismatch-problem. In literature two types of models are used to explain markets for certain occupations: the cobweb-model and the rational expectations model. Sections 2 and 3 provide an overview of the implications of these theories with respect to the market for teachers. Both theories provide a completely opposite characterisation of this market. While from the point of view of the cobweb-theory the market for teachers is expected to be very problematic, from a rational expectations point of view it is expected to function rather well. Both theories do not take into account a factor which seems to be crucial in anticipating behaviour. This is the capability to forecast. In section 4 a model is introduced which takes this capability into account. This model combines the aspects which are typical for the cobweb model and the rational expectations model: variability and predictability.

In section 5 the market for primary school teachers is introduced by the provision of some general statistics with respect to the theory of section 4 . In sections 5 and 6 two models are estimated which explain the enrolment at the teacher colleges. In the first model, policy

1. Commissie Prognose Primair Onderwijs, Vraag en aanbod in het primair onderwijs 19881993. (Demand and Supply in Primary Education 1988-1993). Publication nr. 15, Den Haag, 1989. 
behaviour is treated exogenous while in the second model policy is seen as, partially, endogenous. For both models the consequences of these estimates with respect to the causes of mismatches are calculated. It turns out that replacement demand and policy influences upon demand are indeed difficult to forecast for students. Demographic changes, on the other hand, are more easily forecast. Finally, section 8 provides some conclusions and policy implications. 


\section{COBWEB THEORY}

Economic literature about educational or vocational choice provides two basic models with respect to the relation between labour market situation and enrolment. In this section the cobweb theory will be investigated while in next section attention will be paid to the rational expectations model.

In the context of educational choice the cobweb model is most frequently used by Freeman $(1971,1989)$. The basis of the cobweb theory is the assumption that students base their choices (falsely) on the present situation at the labour market. Suppose there is a shortage of teachers, which is revealed by high wages, low unemployment rates or relatively good working conditions. In such a situation it will be attractive to become a teacher. Therefore, many students, expecting these circumstances to continue until their entrance at the labour market, will choose to start a vocational training to become teacher. After four years (the length of the training period) all these students will enter the market. The shortage will turn into a surplus. This surplus will make the job of teacher less attractive, which will decrease enrolment, etc. As a consequence of this mechanism the supply of teachers will show a cycle-pattern of alternately shortages and surpluses.

The extent of this cobweb phenomenon will depend on some characteristics of the labour market segment involved. Factors which are positively influencing the mismatches are:

- The length of the curriculum

- A low potential mobility to other occupations

- An inelastic demand

- A strong reaction of students to the labour market situation

The market for teachers, in the Netherlands, shows at least three of these four characteristics. Firstly, the curriculum takes four years. Secondly, a qualification from the teachers' training college does not provide many job-opportunities outside the teacher-market. De Grip, Heijke and Dekker (1989) measure the flexibility of educational groups with respect to occupation, by using the Gini-Hirschman-index. ${ }^{2}$ The group to which primary school teachers belong have a

2. The Gini-Hirschman-index is defined as $G H=\left(1-\sum p_{i}^{2}\right) \frac{n}{n-1}$ (n is the number of occupations) in which $p_{i}$ is the fraction of students with a certain education who have a certain occupation i. If people with this education are spread uniform over the occupations $\left(p_{i}=\frac{1}{n}\right.$ for every $\left.i\right)$ the index equals 1 . If all people with this education are concentrated in one occupation the index becomes 0 . 
$-4-$

flexibility 0.37 at a scale between 0 (no flexibility) and 1 (total flexibility). This result is rather low. Only four out of the 53 educational groups show less flexibility. Thirdly, the demand for teachers will be rather inelastic since demand is determined by policy decisions and not by free market forces.

The mismatches, frequently observed at the Dutch market for teachers, therefore seem to fit very well into the cobweb model. 


\section{RATIONAL EXPECTATIONS THEORY}

A completely different vision with respect to the market for teachers is provided by the rational expectations theory. In contrast with the assumptions of the cobweb theory, e.g. Siow (1984) and Zarkin $(1983,1985)$ suggest that student will base their choice between different courses on rational expectations about the future labour market. Students try, just like other economic agents, to maximise their utility. If they have to decide whether or not to enter a teachertraining, they will predict as well as possible the future labour market situation. Students will not be foolish and assume that the future situation will be the same as the present situation, because they can gain from a more sophisticated view. The only reason which might explain a mismatch between supply and demand is a change which was totally unpredictable at the moment the choice was made.

For a characterisation of the market for teachers this change in view has enormous consequences. In a cobweb-model the market for teachers is a prototype of a market with mismatch problems, due to the length of the curriculum, the low potential mobility and the inelastic demand. The rational expectations theory claims, on the other hand that there will be large matching problems only if the future labour market is largely unpredictable. But as Zarkin (1985) states about the market for teachers, 'this market has an obvious special feature. The primary driving variable is the number of children enroled in school, which is essentially deterministic once people are born. This feature makes the task of forecasting future demand conditions much easier'. ${ }^{3}$ According to Zarkin the market for teachers must be one of the best predictable markets, since the number of children determines the demand for teachers. Therefore, from a rational expectations point of view, one might expect few mismatch problems with respect to teachers.

This result seems to contradict the Dutch experience that the market for teachers often shows quite large mismatches. This observation indicates that rational expectations theory is not a good explanation for educational choices, or that the presumption that the future teachers market is largely predictable does not hold. Furthermore, the empirical justification of the rational expectations hypothesis in the theory of educational choice is difficult. Zarkin (1983) tries to compare the cobweb model with his rational expectations model, but does not provide a real test between both hypotheses. On the other hand he observes 'that perhaps the most striking feature is that overall the cobweb model fits the data about as well as the forward

3. Zarkin (1985), p. 410. 
$-6-$

looking, i.e. rational expectations model'. ${ }^{4}$ Siow (1984) gave an empirical justification of the rational expectations model, but recently Connelly (1989) has shown that the indicators Siow used to proof his hypothesis, might also be explained from cobweb-theory.

4. Zarkin (1983), p. 91. 


\section{PREDICTABILITY AND VARIABILITY}

In the case of the market for teachers, two different theoretical points of view lead to very opposite characterisations. The cobweb-theory predicts the market for teachers to be sensitive to mismatch problems, while rational expectation theory predicts few problems. The Dutch experience would therefore suggest the cobweb model to be the most appropriate.

There is, however, besides the testing problems, a theoretical problem with this cobwebexplanation. If it is concluded that the market is cobweb-like, this does not explain why it is cobweb-like. In fact, cobweb-theory assumes that independently of the situation of the market, students do not anticipate future developments. But in a market with many matching problems it is hard to believe students will not take these problems into account. If the cobweb theory is right, the most appropriate policy would be to inform students about the danger to base their decisions on the present labour market situation and to tell them they should anticipate the future. If this was the only thing needed to overcome the mismatch problems, one could wonder why it had not already happened.

It will be intuitively clear that the situation is much more complicated. Not only the notion that one has to anticipate the future labour market, but also the ability to do this will be a relevant factor. Agents' impotence to calculate the rational expectation is one of the major points of criticism of the rational expectations hypothesis (e.g. Spear, 1989). In this section a model is presented which provides a more useful framework for the study of students' anticipations, which explicitly takes into account students' inability to predict the future labour market situation.

In section 2 it is stated that students are considered too naive by the cobweb-assumption that they do not anticipate future developments. In a market full of changes it is unlikely that students completely ignore these changes.

On the other hand, the rational expectations theory is also often considered as unrealistic, because it presumes students to be too sophisticated. In fact Zarkin (1985) indicates the problem with rational expectations by the statement: 'This market has the special feature that future demand conditions can be readily forecast'. ${ }^{5}$ This is, from a rational expectations point of view, no argument to expect proper anticipations. The rational expectations argument for few mismatch problems would be the special feature that future demand conditions can be

5. Zarkin (1985), p. 440. 
largely forecast. The dictionary defines 'readily' as 'without difficulty', which is not an argument in the rational expectations thought. Rational expectations theory only distinguishes between a predictable and an unpredictable part. The prediction is accurate if the predictable part is relatively large ('largely' is defined as 'to a great or preponderating extent').

What is needed to make students anticipate the future labour market is not only the insight that they should anticipate, but also their capability to do so.

Suppose students have to anticipate $x_{t+d}$, a variable which is relevant for their decision, at a moment $d$ years after the moment of choice $t$. Students are assumed to be able to make a forecast but only with an error:

$$
\text { (1) } \quad x_{t+d}^{\exp }=x_{t+d}+\epsilon_{t} \quad \text { with } \quad E\left\{\epsilon_{t}\right\}=0 \text { and } \quad \operatorname{VAR}\left\{\epsilon_{t}\right\}=\sigma_{\text {exp }}^{2}
$$

The assumption that the expectation of the forecast-error is zero does not indicate students' ability to make appropriate forecasts, but represents the fact that there is no reason (from both the researchers and students point of view) to expect an upward or a downward bias beforehand.

Students make a forecast error but furthermore it is assumed that they realise that they are likely to make such an error. This assumption is in contrast with the usual way of modelling imperfect forecasts. Hart (1937) already wrote that '[w]ether his estimates are in fact correct is not an issue in this connection, so long as he has no doubts of their accuracy' ${ }^{6}$

Because students are assumed to realise that their expectation includes an error, they realise that other forecasts might be valuable to them. Therefore they might, apart from their expectation based on theoretical arguments, also use 'theory-less' indicators of the future value $x_{t+d}$. The current value of $x_{t}$ might be such a 'theory-less' or a priori forecast.

The usefulness of such an indicator depends on the meaning of $x$. For example, if $x_{t}$ denotes a price, it might be reasonable to use its current value as a proxy for its future value. The price contains some information about its subject and without further theoretical arguments it is impossible to expect it to go down or to rise.

6. Hart (1937), p. 277. 
This theory-less forecast $x_{t}$ of the future $x_{t+d}$, will also contain an error $x_{t+d}-x_{t}$, and the variance of this error is denoted as:

(2) $E\left\{\left(X_{t}-X_{t+d}\right)^{2}\right\}=\sigma_{\text {var }}^{2}$

This assumption is similar to the argument used for myopic or cobweb expectations. Kaldor (1934) states that an 'assumption consistent with the degree of abstractness necessary for the generalisations of pure theory' is '[a]ll individuals expect the prices actually ruling to remain in force permanently: no price-changes are anticipated'. The difference is that cobweb-theory assumes this expectation to be the final prediction, while in the model to be developed here it is assumed that the myopic expectation is the forecast before any theoretical consideration has been made. As soon as students recognise that this myopic expectation leads to cycles, they will adjust their prior expectation and will take this theoretical notion into account. In the model presented here all this theoretical information is contained in $x_{t+d}^{\exp }$.

By using both sources of information, students can form a prediction which minimises their prediction error by mixing $x_{t}$ and $x_{t+d}:^{8}$

(3) $\quad x_{t+d}^{\text {pred }}=\lambda x_{t}+(1-\lambda) x_{t+d}^{\exp }$ with

(4) $\lambda=\frac{\frac{1}{\sigma_{\text {vax }}^{2}}}{\frac{1}{\sigma_{\text {var }}^{2}}+\frac{1}{\sigma_{\text {exp }}^{2}}} \quad$ and

(5) $\sigma_{\text {pred }}^{2}=\frac{1}{\frac{1}{\sigma_{\text {var }}^{2}}+\frac{1}{\sigma_{\exp }^{2}}}$

The superscript 'exp' refers to expectations sec, while 'pred' refers to expectations which are adjusted by recognising that the expectations are not perfect. This leads to predictions which are a mix between the best possible forecast (which includes a forecast error) based on students' information and theoretical insight, and the mean of the theory-less prior distribution,

7. Kaldor (1934), p. 123.

8. The same result can be obtained by constructing $x_{t+d}^{\text {pred }}$ from a bayesian inference from a prior distribution with mean $x_{t}$ and variance $\sigma_{v a r}^{2}$, and by treating expectation $x_{t+d}^{\exp }$ as information about $x_{t+d}$. (3), (4) and (5) follow under the assumption of normal distributed error terms. 
in this case the value of $x$ at $t$.

The ratio between $\lambda$ and $1-\lambda$, which indicate the weights of the mix, are equal to $\frac{\mathbf{\sigma}_{\mathrm{var}}^{2}}{\sigma_{\exp }^{2}}$ :

(6) $\frac{\lambda}{1-\lambda}=\frac{\sigma_{\text {exp }}^{2}}{\sigma_{\text {var }}^{2}}$

If students' capability to make forecasts increases, i.e. $\sigma_{\exp }^{2}$ decreases, then $\lambda$ will decrease which implies that this expectation will be used to a larger extent, while if the stability of $\mathrm{x}$ increases, i.e. $x$ is less sensitive to changes ( $\sigma_{\text {var }}^{2}$ decreases), then the expectation will be used to a smaller extent, since there is less need to anticipate future developments.

Cobweb-theory and rational expectations might be seen as extreme situations in this model. In a cobweb model $\sigma_{\text {exp }}^{2}=\infty$. Students are completely unable to make forecasts. Therefore $\lambda=1$ and $X_{t+4}^{\text {pred }}=X_{t}$. In the rational expectations theory $\mathrm{x}$ has to be split up into two components. The component which is predicted by the researchers model is perfectly predictable (i.e. the rational expectation forecast) while the other component is totally unpredictable (i.e. the unpredictable innovation).

Therefore cobweb theory might be typified as the theory of variability while rational expectations is the theory of predictability. From the cobweb point of view mismatches are expected in case there is a market with variability. If the aspects of the market situation which are relevant to students are very variable, large mismatches will occur. The rational expectation theory, on the other hand, predicts mismatches to occur when future variables are largely unpredictable.

In next section the labour market for Dutch primary school teachers is taken into account, in which several components of the demand for labour are examined with respect to both variability and predictability. 


\section{THE MARKET FOR PRIMARY SCHOOL TEACHERS}

In this section the Dutch market for teachers at the primary school will be investigated within the framework of the model provided in the previous section. Students' decision to go to a teacher training depends on their predictions about the future labour market situation. Over the years teacher training in the Netherlands has passed through several changes. Until 1967 the regular course took four years, but there were possibilities to enter the program after the first or second year for students with a higher preliminary education. The extent to which these sideentrances were used changed slowly throughout the years. Furthermore, it was possible to extend the study with an additional fifth year, to get an additional qualification. In the empirical analysis only the students who followed the entire program (four years) are taken into account. Furthermore, the assumption is made that all students intend to leave the school after four years. In 1968 the program became three years without further possibilities for side-entrance or extension of the curriculum. Therefore, the time-lag between the choice for the teacher training and the entrance at the labour market has been set on three years from 1968 till 1983.

In fact, not only the situation of the market at the moment one enters the market is important, but also the situation during the whole teaching-career. Since the Dutch tenure system protects employed teachers against teachers entering the market, this facet is not taken into account. Therefore supply will depend on the prediction about the future labour market $d(d=3,4)$ years in advance:

(7) $\quad C_{t}=f\left(x_{t+d}^{\text {pred }}\right)$

in which $\mathrm{x}$ represents the relevant factors affecting students' choices, such as wages, probability to get a job and working conditions. Because on the one hand, not every student will enter the labour market (e.g. school drop-outs) and on the other hand other students might enter, e.g. those who followed a shorter program, the supply, d years after the choice is assumed to be a factor $A_{t}$ of the enrolment.

(8) $S_{t+d}=\frac{C_{t}}{A_{t}}$

Since it is difficult to determine which factors are relevant, and since there are no adequate data on possible factors, $x$ will be taken into account only implicitly. As stated in section $1, x$ will be affected by the demand for teachers. By treating the demand for labour as exogenous every $D_{t}$ can be associated with a $x_{t}$ which clears the market (i.e. $S_{t}=D_{t}$ ). 
(9) $x_{t}=g\left(D_{t}\right)$

A combination of (7) and (9) leads to

(10) $\quad C_{t}=f \circ g\left(D_{t+d}^{\text {pred }}\right)$

If expected demand is substituted by realised demand this equation should be equal to the market-clearing condition $S_{t+d}=D_{t+d}$. Taking into account the factor between enrolment and supply at the market ( 8 ) gives:

(11) $\quad C_{t}=A_{t} \cdot D_{t+d}^{\text {pred }}$

Figure I: Total demand

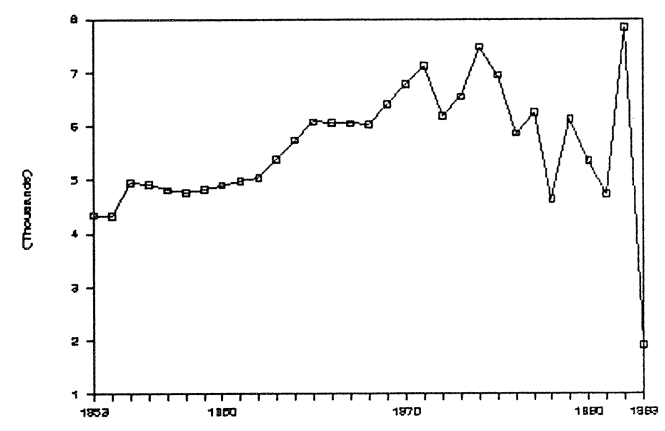

In formula (11) the enrolment-decision depends on the prediction of the future demand for teachers. The demand for teachers is depicted in figure $1 .{ }^{9}$ In the statistics used as source for these data, replacement demand ${ }^{10}$ has been distinguished from extension demand. Furthermore, it is possible to split up the extension demand into a demographic component and a policy component. The demographic component is constructed by imposing the student/teacher ratio from year $\mathrm{t}$ upon the change in the number of children at primary school between year $t$ and year $t+1$. This figure indicates the demand for teachers that would be created due to a growth in the number of children under the assumption that the average size

9. For a description of the data see the appendix.

10. Replacement demand is defined as 'the number of teachers needed to replace teachers who left, as far as they leave a vacancy. Cancelled places have been counted as extension demand, in a negative sense' (translated from Dutch), C.B.S. (1953), p. 5. From 1958 till 1971 replacement demand was not measured every year. In the estimations in the next two sections these missing values have been replaced by interpolations (see appendix). 
of the classes does not change. The remaining part of the extension demand is called the policy component, because it is caused by (intended or unintended) changes in student/teacher ratio. The changes might be caused by explicit governmental decisions about the size of the classes, but might also occur due to the flexibility of the system which allows schools to employ a number of teachers within certain limits. This kind of changes is also classified in the policy component. Although the decision to change the ratio between teachers and pupils in this case is not directly taken by the government, they indirectly did so by allowing for a certain flexibility of the system.

The demand for teachers can therefore be split up into:

$$
D_{t}=R e p I_{t}+D e m_{t}+P O I_{t}
$$

Figure II, III and IV show these components of the demand for teachers. These data make it possible to calculate the variability of the three components. To adjust for the changing scale the variability of the components of demand, is defined as:

$\operatorname{VRR}\{R e p I\}=\frac{1}{T} \sum_{t}\left(\frac{R e p I_{t}-R \in p I_{t-1}}{D_{t}}\right)^{2}$

$$
\begin{aligned}
& \operatorname{VAR}\{D e m\}=\frac{1}{T} \sum_{t}\left(\frac{D e m_{t}-D e m_{t-1}}{D_{t}}\right)^{2} \\
& \operatorname{VAR}\{P O I\}=\frac{1}{T} \sum_{t}\left(\frac{P O I_{t}-P O I_{t-1}}{D_{t}}\right)^{2}
\end{aligned}
$$

Figure II: Replacement demand

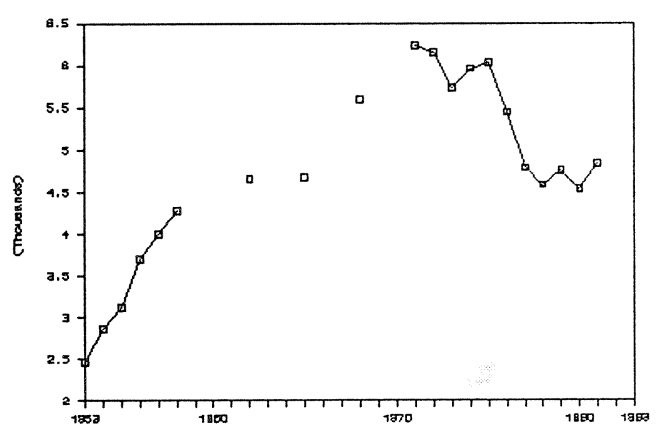

Figure III: Demographic component

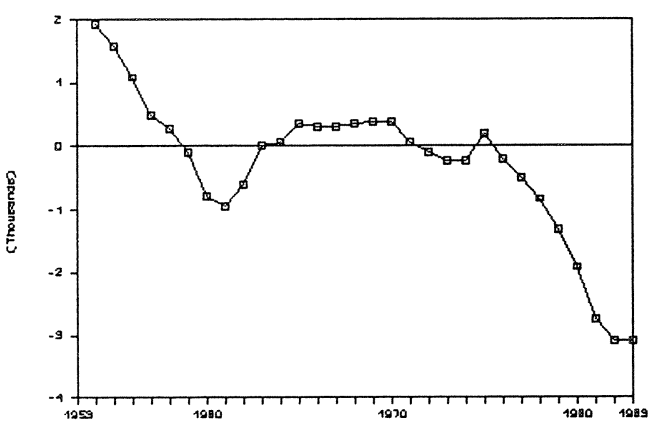


Figure IV: Policy component

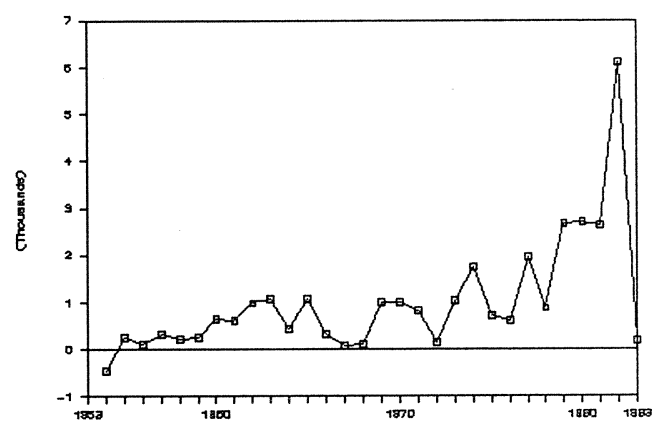

In table 1 this variability is indicated for a period in the fifties, a period in the seventies and the total period. In the fifties demographic changes were the most important cause of variation. In the course of time the importance of this cause has diminished considerably, while the variability of the two other components, the replacement demand and the policy component has grown. For the period as a whole the policy component is the most important factor, with replacement demand very close to it. The demographic component is much less important.

This is an important objection against Zarkin's hypothesis. The idea that the demand for teachers is largely determined by these demographic changes is, at least for the Netherlands, not true. The two other components, replacement and the policy component, appear to be much more important.

Table 1. Variability and predictability of the demand for teachers

\begin{tabular}{|c|c|c|c|c|}
\hline & \multicolumn{3}{|c|}{ variability $^{11}$} & \multirow[t]{2}{*}{ predictability } \\
\hline & $50--^{\prime} 60$ & $' 70-' 80$ & '50-'80 & \\
\hline replacement & 0.006 & 0.080 & 0.042 & moderate \\
\hline demographic & 0.032 & 0.005 & 0.017 & good \\
\hline policy & 0.006 & 0.027 & 0.057 & bad \\
\hline
\end{tabular}

The table does not provide a measure of the variability of supply. This is the case because supply is modelled as a reaction to demand. But there also might be changes in supply that will change the equilibrium situation. Firstly, the preferences of students might change. Secondly, it

11. For replacement demand the fifties measurement of the variability is based on the period 1951-1958 while for the demographic and policy component the period 1954-1961 has been used. The seventies measure is based on the period 1971-1981. 
might be possible that some students anticipate the forecast errors of others. Thirdly, due to mismatches a stock of unemployed teachers might exist, which is large after years of excess supply and which is small if supply has been too small.

These three supply side factors are not taken into account, simply because there are no data about them. For changes in preferences it might be argued that they will not be very important since they will be very slow changes and in the analyses only unexpected changes matter. Forecasts of other students' forecast-errors might also be seen as unrealistic. The stock of unemployed teachers might, however, be a rather important factor at the market for teachers. This might make the estimates less reliable but has no influence upon the assignment of the causes of mismatches to the three components, since changes in the stock of unemployed are ultimately caused by the unexpected changes in demand.

A second problem is the direct measurement of the predictability of future changes. The predictability largely depends on the method which is used by the students. One way, mostly used, to measure the predictability is to impose a certain forecast-rule on the model. A forecastrule is a function which makes the expectation dependent on information known at the moment of choice. 'Adaptive expectations' are an example of such a forecast rule. The prediction error can then be measured by comparing the prediction which follows from the forecast-rule with the realisation. ${ }^{12}$ This method does not provide a satisfactory result. This measure of predictability heavily depends on the form of this forecast-rule, while there is no valid reason to prefer one rule above the other.

In this section the predictability will only be indicated roughly on intuitive grounds. In section 6 and 7 a model of students behaviour will be estimated. The results of the estimators can be used to measure indirectly the predictability of labour market changes.

In table 1, the predictability of the demographic component of the extension demand has been scaled as good. This is in accordance with Zarkin's (1985) argument. To predict the demographic changes one can use simple statistics. Furthermore, these observations about a growth or decline in the number of children born, are mostly publicly known. It can be assumed therefore that students know the developments with respect to demographic changes.

The predictability of replacement demand will be much more difficult. Replacement demand of course also depends on certain demographic figures, namely the age-composition of the teachers already working, but the link between these figures and replacement demand is more

12. See e.g. Smyth (1973), Turnovski (1978) and Freebairn and Withers (1979). 
complex, while the figures themselves will be less known.

The third component, extension demand due to policy-changes will be, however, even more difficult to predict. Policy changes mostly occur rather unexpected, while it should be necessary to know them three or four years in advance. Furthermore, it is not possible to connect policychanges directly with certain statistical figures as is possible for the two other components.

Based on the measured variability and the intuitively indicated predictability the following, preliminary, conclusion can be drawn. By splitting future demand up into three components, replacement demand, a demographic and a policy component of extension demand it appears that the demographic component has the smallest variation and is the best predictable component. In the Dutch situation it is therefore insufficient to take only this component into account while studying the labour market for teachers. Replacement demand appears to be a more important component and also is less predictable, while the policy component is even more dominant and also more difficult to predict. It is therefore more obvious to explain the mismatch problem at the market for teachers by reference to these two components of the demand.

In the next section a model explaining the enrolment of students at the teacher training is estimated. Indirectly, the results give more information about the predictability of the several components of demand. These components have been treated as exogenous variables. It is, however, possible that policy changes are not random, but are to some extent reactions to shortages and surpluses at the market. The institutions will for example be flexible to a certain extent which might lead to an adjustment of the demand to the market situation. In section 7 this will be investigated: the policy component will be viewed as endogenous. On the other hand it is also possible that a substantial part of replacement demand is, alternately, caused by policy changes. New policies might make the job 'teacher' less or more attractive, resulting in a decrease or increase of the outflow of teachers. An example of this might be the introduction of early retirement. With the data used in this paper it is, not possible to measure such links. Replacement demand will therefore be treated as exogenous. 


\section{ENROLMENT WITH EXOGENOUS POLICY}

In section 4 a framework has been presented to model students' expectations with respect to the future labour market situation. The aim of this section is to explain, departing from this expectations-framework, students' enrolment at the teacher training. A combination of the enrolment-function (11) and the demand-function (12) gives:

$$
C_{t}=A_{t} \cdot\left(\operatorname{Rep}_{t+d}^{\text {pred }}+D e m_{t+d}^{\text {pred }}+\text { PoI }_{t+d}^{\text {pred }}\right)
$$

The predictions have been modelled in section 4 as:

$$
\begin{aligned}
& R e p I_{t+d}^{\text {pred }}=\lambda_{R} \operatorname{Rep} I_{t}+\left(1-\lambda_{R}\right) \operatorname{Rep} I_{t+d}^{\exp } \\
& \text { (15) } D e m_{t+d}^{\text {pred }}=\lambda_{D} D e m_{t}+\left(1-\lambda_{D}\right) D e m_{t+d}^{\exp } \\
& \text { POI } \begin{array}{c}
\text { pred } \\
t+d
\end{array}=\lambda_{P} P O I_{t}+\left(1-\lambda_{P}\right) P O I_{t+d}^{\exp }
\end{aligned}
$$

Furthermore, a specific form for $A_{T}$ has to be taken:

$$
A_{t}=\alpha_{0}+\alpha_{1} t+\alpha_{2} t^{2} \quad \text { with } \quad t=1 \text { in } 1946
$$

Since the forecast-errors do not correlate with the realised demand, e.g. $R e p I_{t+d}$, these realisations can be used as approximates for the expectations of these realisations.

It takes three or four years before wrong predictions are falsified by realisations. Therefore errors might persist some years which cause autocorrelation in the errors. Therefore an $A R(1)$ error-term has been added, indicated by a parameter $\rho$.

To adjust for changes in scale and to make the results comparable with the variability measure of section 5 ,equation (14) is estimated by least squares, with the observations weighted with total demand. The results are shown in table 2. 
Table 2. Estimation results of equation (14)

\begin{tabular}{llll}
\hline$R^{2}$ & 0.510 & & \\
DW & 1.876 & & \\
& parameter & t-statistic & \\
\hline$\rho$ & 0.36 & 1.13 & \\
$\alpha_{0}$ & 0.6540 & 0.61 & \\
$\alpha_{1}$ & 0.0257 & 0.22 & tof $1-\lambda$ \\
$\alpha_{2}$ & -0.0001 & 0.05 & 0.15 \\
& & & 0.59 \\
$\lambda_{R}$ & parameter & tof $\lambda$ & 0.46 \\
$\lambda_{D}$ & 0.93 & 1.90 & \\
$\lambda_{P}$ & 0.69 & 1.32 & 2.68 \\
\hline
\end{tabular}

Equation 4 gives the link between $\lambda$, the variability and the predictability. This can be rewritten as:

(17) $\quad \sigma_{\exp }^{2}=\frac{\lambda}{1-\lambda} \sigma_{\operatorname{var}}^{2}$

Therefore, the predictability of the components of the future demand can be calculated. In the usual literature, estimates of the predictability largely depend on the forecasting-rule that has been adopted. In the approach followed here, the results depend on the correctness of the enrolment-function (equation (14)). In the next section a slightly different model will give slightly different results. Furthermore, the calculation of $\sigma_{\exp }^{2}$ might have a bias since it is a non-linear function of $\lambda$ and $\sigma_{v a r}^{2}$.

Table 3 shows the variability and predictability of the three components of demand.

Table 3. Variability and predictability of demand

\begin{tabular}{lll} 
& variability & predictability \\
\hline replacement & 0.042 & 0.558 \\
demographic & 0.017 & 0.038 \\
policy & 0.057 & 0.323 \\
\hline
\end{tabular}


The ranking of the three components with respect to predictability is not completely in accordance with the intuition of section 5 . The predictability of the demographic component is indeed very good, but the policy component of demand is, according to table 3 better predictable than the replacement demand. This result might be explained by the endogenous character of policy changes. If policy reacts on supply-surpluses or shortages, there is a link between enrolment and policy changes, but the causation is alternately. In the next section a model will be examined in which this possibility is taken into account.

A combination of (4) and (5) gives:

(18) $\quad \sigma_{\text {pred }}^{2}=\lambda \sigma_{\text {var }}^{2}$

This is the variance of the prediction errors which remain after students have adjusted their expectations because of inaccuracy. This variance of the prediction error can also be written as

(19) $\sigma_{\text {pred }}^{2}=\lambda^{2} \sigma_{\text {var }}^{2}+(1-\lambda)^{2} \sigma_{\exp }^{2}$

by using the calculation rules for the variance. Equation (19) shows that the prediction error consists of a systematic part $\left(\lambda^{2} \sigma_{\text {var }}^{2}\right)$ and an unsystematic part $\left((1-\lambda)^{2} \sigma_{\exp }^{2}\right)$. The systematic part is a fraction of the difference between demand at the moment the choice was made and the moment of the entrance at the labour market. Figure $V$ gives the realisations of this part of the prediction error. It yearly provides the predicted surpluses of students who enter the market for teachers. Figure VI, VII and VIII provide the same data with respect to replacement demand, the demographic component and the policy component. It is important to note that the total prediction error exceeds the error illustrated. The graphs only provide this systematic component of the error, which is only a $\lambda$-fraction of the total variance. These figures are denoted in table 4. 
Figure V: Systematic error (surplus in enrolment)

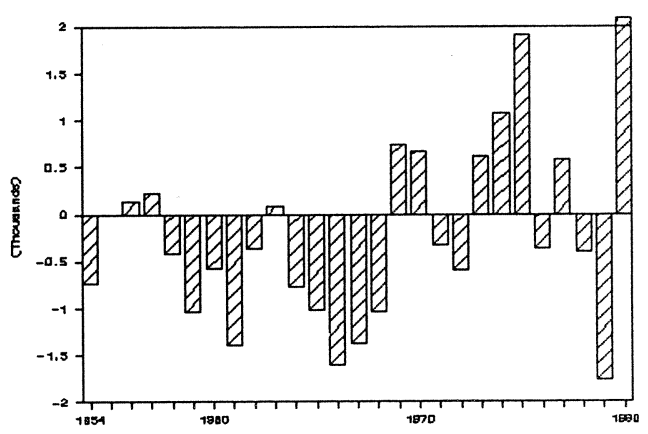

Figure VII: Mismatch demographic (surplus in enrolment)

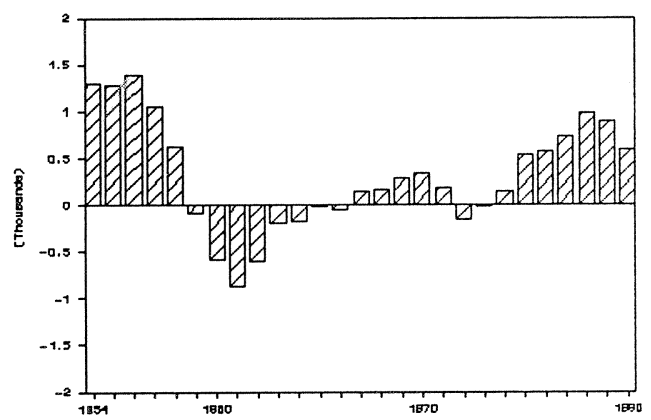

Figure VI: Mismatch replacement (surplus in enrolment)

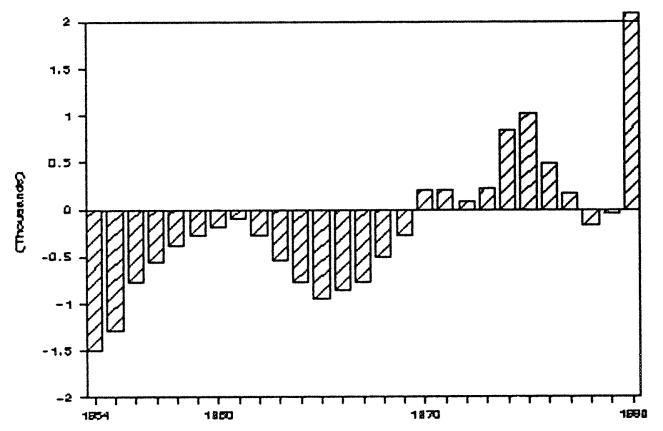

Figure VIII: Mismatch policy (surplus in enrolment)

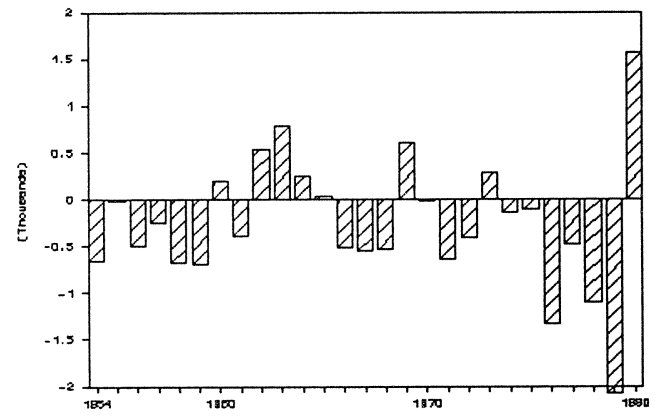

Table 4. The prediction error

\begin{tabular}{lll}
\hline & $\sigma_{\text {pred }}^{2}=\lambda \sigma_{\text {var }}^{2}$ & systematic part $\left(\lambda^{2} \sigma_{\text {pred }}^{2}\right)$ \\
\hline replacement & 0.039 & 0.036 \\
demographic & 0.012 & 0.008 \\
policy & 0.048 & 0.041 \\
\hline
\end{tabular}

The unsystematic part of the prediction error can not be measured directly. Figure IX provides data about the residuals of the estimation. These might partly consist of these unsystematic errors, but also other kinds of specification errors are included in these figures. 
Figure IX: Residuals (enrolment)

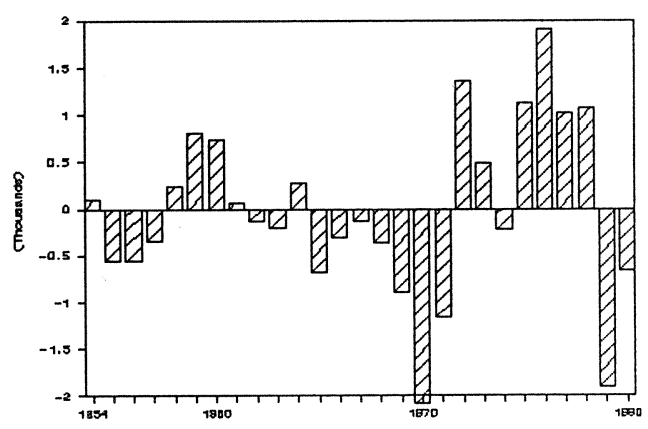

The extent to which the unsystematic part of the prediction error affects these residuals depends on the correlation of this part of the prediction error with individuals. If everyone makes the same errors, they will be reflected completely in the residuals, but if the errors will compensate each other, this will lead to a zero-error on the aggregate level. In that case the market is not influenced by this error. This does not mean that the error has no consequences. Due to differences in the predictions, some students will become teachers who did not want to, while others do not become teacher although they had wanted to, if they had known the labour market situation. 


\section{ENROLMENT WITH ENDOGENOUS POLICY}

The model of section 6 is based on the assumption that the three components of the demand for teachers are exogenous. Whether this assumption is true for the policy component is highly doubtful. Firstly, policy instruments might be used just to compensate for mismatches at the market. In a situation of shortages government might decide for instance to increase the pupil/teacher ratio. Secondly, these adjustments of the policy component of demand might occur not because of an explicit policy decision but unintendedly, due to the flexibility of the system. Governmental rules with respect to the number of teachers a school is allowed to employ are not totally exact but may allow some flexibility.

In this section the model is adjusted to make such policy reactions to shortages and surpluses possible. Therefore the enrolment-function (14) is changed into:

$$
C_{t}=A_{t} \cdot\left(\operatorname{Rep} I_{t+d}^{\text {pred }}+D e m_{t+d}^{\text {pred }}+E x P O I_{t+d}^{\text {pred }}\right)
$$

The difference with (14) is that supply does not anticipate the policy component of demand any more, but only its exogenous part ExPol. The predictions are:

$$
\begin{aligned}
& \operatorname{Rep} I_{t+d}^{\text {pred }}=\lambda_{R} R e p I_{t}+\left(1-\lambda_{R}\right) \operatorname{Rep} I_{t+d}^{\exp } \\
& D e m_{t+d}^{\text {pred }}=\lambda_{D} D e m_{t}+\left(1-\lambda_{D}\right) D e m_{t+d}^{\exp } \\
& \text { EXPOI } I_{t+d}^{\text {pred }}=\left(\mu_{P} 0+\left(1-\mu_{P}\right) P O I_{t}\right)+0 \cdot \operatorname{EXPOI}_{t+d} \\
& =\left(1-\mu_{P}\right) \text { POI }
\end{aligned}
$$

The predictions for replacement demand and the demographic component are unchanged. It is assumed that the exogenous changes in the policy component of demand are totally unpredictable $\left(\sigma_{\text {exp }}^{2}=\infty\right)$. Therefore this term is excluded $\left(\lambda_{P}=1\right)$. Furthermore, because the policy component is partly endogenous, it is not likely students will treat the present policy component as a prior for future policy demand. Therefore students' predictions consist of a mix between 0 , i.e. no future policy demand, and the present policy demand. The larger the $\mu_{P}$, the more students expect present policy demand to be incidentally. 
Furthermore, it might be possible to explain the policy component of demand as a reaction to shortages or surpluses in supply. The model provides two types of errors: the systematic error explained by the model and the residuals $\varepsilon$ of the estimation. The systematic error is called $E_{t}^{1}$ and the unsystematic error is called $E_{t}^{2}$. By dividing them by $A_{t}$ they become comparable to the policy component of demand.

(22) $E_{t}^{1}=\lambda_{R}\left(R e p I_{t+d}-R e p I_{t}\right)+\lambda_{D}\left(D e m_{t+d}-D e m_{t}\right)$

(23) $E_{t}^{2}=\frac{\mathbb{\varepsilon}}{A_{t}}$

The policy component of demand might depend on both these enrolment-errors.

(24) $P O I_{t}=C+\gamma_{1} E_{t-d}^{1}+\gamma_{2} E_{t-d}^{2}$

Table 5 provides the estimation results of equation (20), while table 6 provides the results of the estimation of equation (24).

Table 5. Estimation results of equation (20)

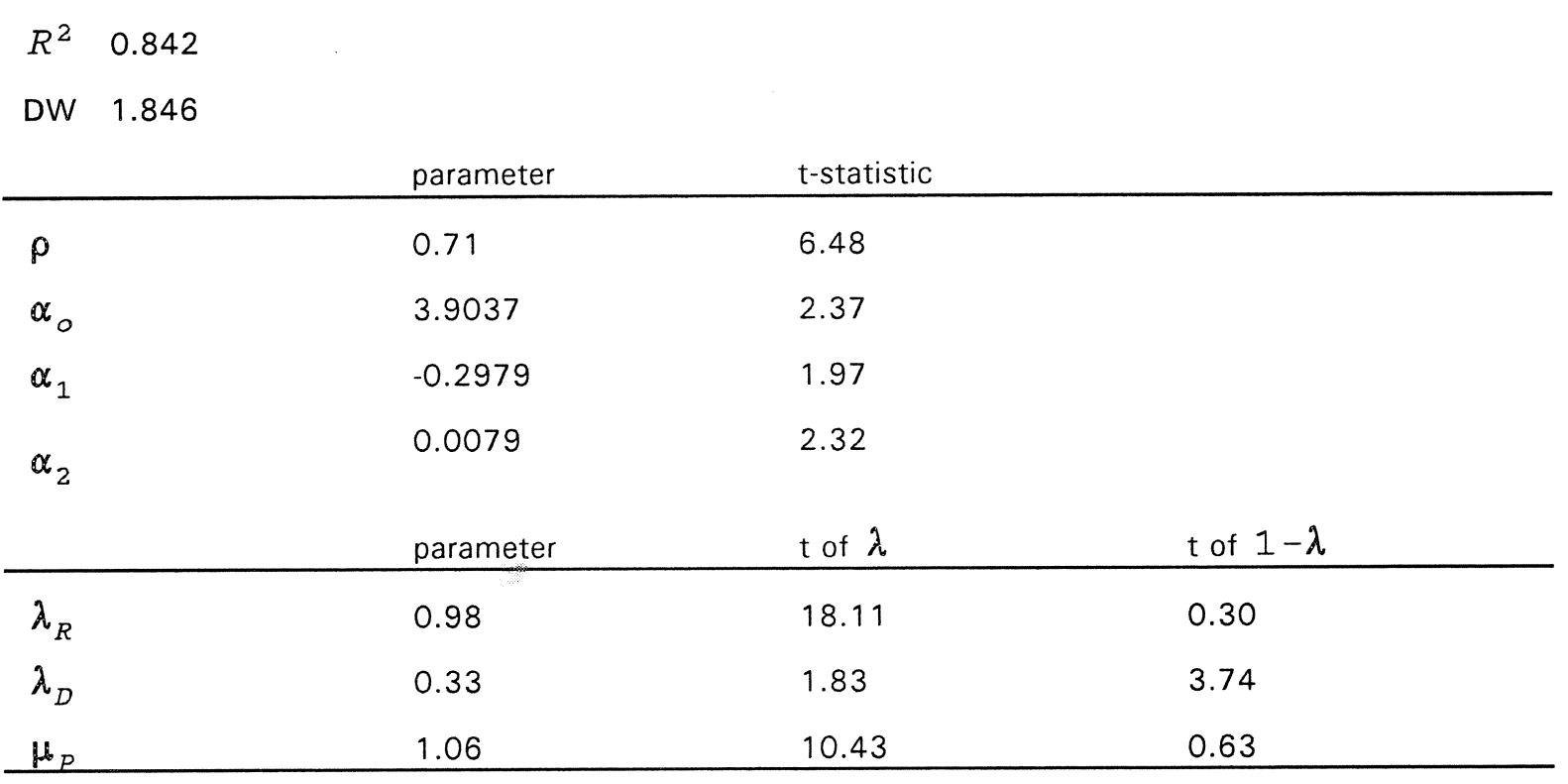


Table 6. Estimation results of equation (24)

\begin{tabular}{|c|c|c|c|}
\hline \multicolumn{2}{|c|}{$R^{2} \quad 0.051$} & parameter & t-stat \\
\hline c & & 1211 & 4.35 \\
\hline$\gamma_{1}$ & & 0.18 & 0.85 \\
\hline$\gamma_{2}$ & & 0.26 & 0.73 \\
\hline
\end{tabular}

Table 5 shows that the estimates for the extent to which future demand is anticipated, decrease, in this alternative model. Furthermore, $\mu_{P}$ is almost 1 which implies that students expect policy to be incidental. Table 7 provides the calculations of the predictability, based on these estimates.

Table 6 shows that the attempt to explain policy demand as a function of surpluses and shortages is not very successful. The $R^{2}$ is very low and both parameters $\left(\gamma_{1}\right.$ and $\left.\gamma_{2}\right)$ are not significantly different from 0.

The relative success of the model with endogenous policy is entirely due to equation (20). This is not caused by the endogenous character of the policy component of demand. It seems that the assumption that students view demand is transitory is correct.

The intuition that the demographic component of demand is the best predictable component is confirmed. The predictability of replacement demand is rather low.

Table 7. Variability and predictability of demand

\begin{tabular}{lll} 
& variability & predictability \\
\hline replacement & 0.042 & 2.058 \\
demographic & 0.017 & 0.008 \\
policy & 0.057 & $\infty$ \\
\hline
\end{tabular}

Table 8. The prediction error

\begin{tabular}{lrr}
\hline & $\sigma_{\text {pred }}^{2}=\lambda \sigma_{\text {var }}^{2}$ & systematic part $\left(\lambda^{2} \sigma_{\text {pred }}^{2}\right)$ \\
\hline replacement & 0.041 & 0.040 \\
demographic & 0.006 & 0.002 \\
\hline
\end{tabular}


Table 8 shows that despite the low predictability of the replacement demand the variance of the prediction error is rather low. This is caused by the possibility for students to use present replacement as an approximation for future replacement. The variance of the prediction will therefore never exceed the variability of the component that is predicted.

Figures $\mathrm{X}, \mathrm{XI}, \mathrm{XII}$ and $\mathrm{XIII}$ give the calculations for $E_{t}^{1}, E_{t}^{2}$, the systematic part of the error in the replacement demand and in the demographic component.

Figure $\mathrm{X}$ : Systematic error (surplus in Figure $\mathrm{XI}$ : Residuals (enrolment) enrolment)
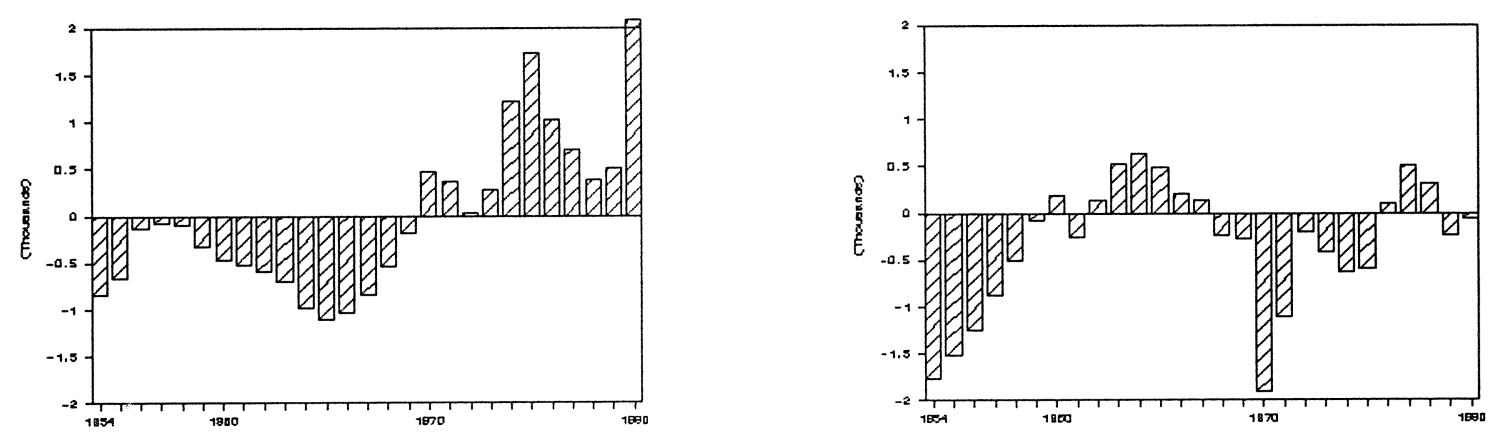

Figure XII: Mismatch replacement (surplus in enrolment)

Figure XIII: Mismatch demographic (surplus in enrolment)
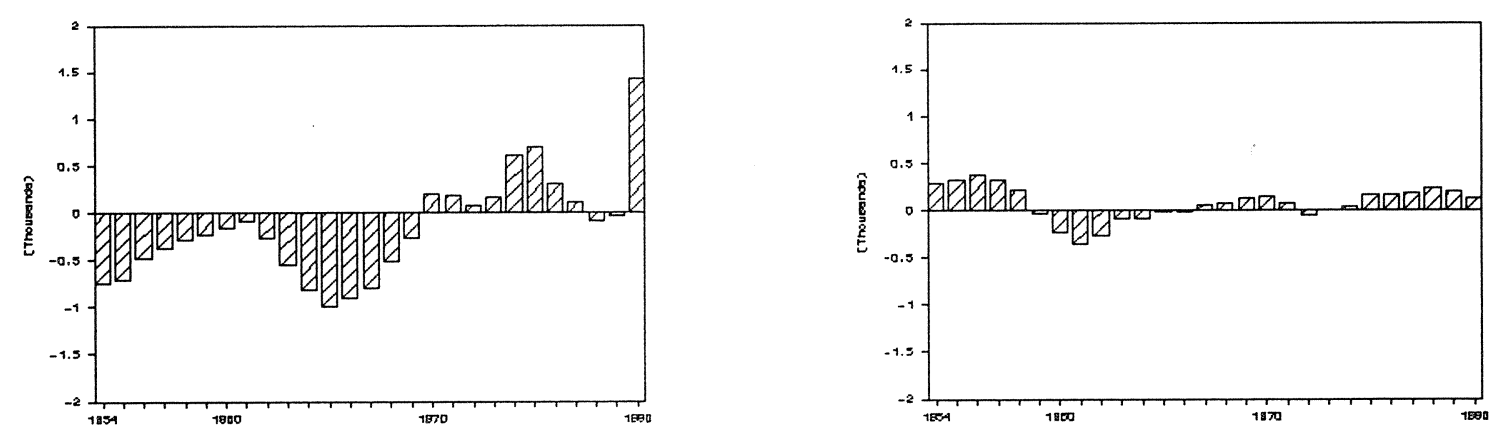


\section{CONCLUSIONS}

This paper departed from the observation that cobweb- and rational expectations theory, which are both used in research with respect to students enrolment, provide completely different predictions with respect to the market for primary school teachers. The large mismatches at the Dutch market for primary school teachers would, at first sight, indicate the appropriateness of the cobweb-model. However, this cobweb-model does not explain why students do not use better predictions of the future labour market situation, from which they would profit.

In this paper an attempt has been made to explain this behaviour by the use of the concepts variability and predictability. In rational expectations literature it is assumed that students dispose of the correct model to predict the future labour market situation. In the framework presented here this assumption is abandoned, and it is assumed that students have a model which is not perfect and which will therefore generate a forecast-error. If the predictability of this model is rather low, it might become useful to exchange the prediction of the model for the naive predictions of the cobweb model. Especially when the variability of the market involved is low the current situation is a good alterative for a bad prediction.

Both the model with exogenous policy (section 6) and the model with endogenous policy (section 7) provide a similar typification of the market for primary school teachers. The demographic component of the demand has a relative low variability, but also a high predictability. Replacement demand and the policy component of demand have, however, a high variability and a low predictability.

Therefore, replacement demand and the policy component of demand seem to be the most important causes of the mismatch problem, while demographic changes seem to have little impact. The model provides two strategies to combat the mismatch problems: a reduction of the variability and an increase of the predictability of replacement demand and policy changes. A reduction in the variability is not feasible for replacement demand. A reduction of the variability with respect to the policy component would imply for policy makers to stick to a certain policy for a longer time or to reduce the flexibility of the system, which both seem to be politically unrealistic.

The other instrument to reduce mismatch problems, therefore, seems more appropriate. For replacement demand it might be possible to improve the quality of expectations by supporting students with professional forecasts of future replacement demand, based on detailed information about the age structure of the teaching staff. The predictability of policy changes will not be improved by econometric investigations. For these policy changes the only 
appropriate solution to increase the predictability and thereby to decrease the mismatches, might be an early announcement of these changes. In order to anticipate correctly, students should know these changes before they decide to enter teacher training. 


\section{APPENDIX: THE DATA}

The data used for estimation has been taken from 'Statistiek van het basisonderwijs; leerlingen en scholen', 'Statistiek van het basisonderwijs; instroom, doorstroom en uitstroom van hoofden en onderwijzers', and 'Statistiek van het beroepsonderwijs: opleidingsscholen voor kleuterleidsters, pedagogische academies' and their predecessors of the Centraal Bureau voor de Statistiek. Some figures which are missing in the C.B.S. publications have been created by interpolation or extrapolation. In the table these figures, and figures based on them, are printed in italics.

\begin{tabular}{|c|c|c|c|c|c|}
\hline year & enrolment & replacement & $\begin{array}{l}D E M A N \\
\text { demographic }\end{array}$ & policy & total \\
\hline 1953 & 2903 & 2474 & 1874 & 0 & 4348 \\
\hline 1954 & 3601 & 2869 & 1912 & -447 & 4334 \\
\hline 1955 & 3564 & 3130 & 1572 & 249 & 4951 \\
\hline 1956 & 3615 & 3712 & 1084 & 126 & 4922 \\
\hline 1957 & 3882 & 4006 & 485 & 324 & 4815 \\
\hline 1958 & 4700 & 4276 & 270 & 218 & 4764 \\
\hline 1959 & 5437 & 4374 & -103 & 261 & 4835 \\
\hline 1960 & 5381 & 4472 & -782 & 651 & 4906 \\
\hline 1961 & 4910 & 4570 & -939 & 598 & 4977 \\
\hline 1962 & 5384 & 4668 & -607 & 987 & 5048 \\
\hline 1963 & 5934 & 4671 & 11 & 1064 & 5395 \\
\hline 1964 & 6080 & 4674 & 74 & 423 & 5741 \\
\hline 1965 & 6115 & 4677 & 350 & 1061 & 6088 \\
\hline 1966 & 6253 & 4982 & 308 & 330 & 6073 \\
\hline 1967 & 6503 & 5287 & 299 & 75 & 6057 \\
\hline 1968 & 6744 & 5592 & 350 & 100 & 6042 \\
\hline 1969 & 7212 & 5807 & 382 & 1001 & 6407 \\
\hline 1970 & 5605 & 6023 & 387 & 1015 & 6771 \\
\hline 1971 & 7366 & 6238 & 71 & 827 & 7136 \\
\hline 1972 & 9648 & 6156 & -101 & 142 & 6197 \\
\hline 1973 & 8829 & 5745 & -226 & 1032 & 6551 \\
\hline 1974 & 9162 & 5966 & -238 & 1753 & 7481 \\
\hline 1975 & 10000 & 6038 & 192 & 724 & 6954 \\
\hline 1976 & 10145 & 5449 & -198 & 617 & 5868 \\
\hline 1977 & 9269 & 4792 & -497 & 1967 & 6262 \\
\hline 1978 & 7311 & 4591 & -826 & 880 & 4645 \\
\hline 1979 & 5721 & 4761 & -1309 & 2677 & 6129 \\
\hline 1980 & 5008 & 4538 & -1913 & 2719 & 5344 \\
\hline 1981 & & 4833 & -2739 & 2629 & 4723 \\
\hline 1982 & & 4833 & -3091 & 6099 & 7841 \\
\hline 1983 & & 4833 & -3096 & 173 & 1910 \\
\hline
\end{tabular}




\section{REFERENCES}

C.B.S. (1953), De voorziening in de behoefte aan onderwijzers bij het lager onderwijs in 1952. Utrecht.

Commissie Prognose Primair Onderwijs (1989), Vraag en aanbod in het primair onderwijs 19881993. Publicatie 15, Den Haag.

Freebairn, J.W. and G.A. Withers (1979), 'Welfare effects of Salary Forecasts Error in Professional Labour Markets'. The Review of Economics and Statistics 61, pp. 234-241.

Connelly, R. (1989), 'Occupational Choice under Uncertainty when Experience is a Determinant of Earnings'. Econometrica 57, pp. 1215-1219.

De Grip, A., J.A.M. Heijke and R.J.P. Dekker (1989), 'The Labour Market by Education and Occupation in 1992'. ROA-R-1989/8E, Maastricht.

Freeman, R.B. (1971), The Market for College-Trained Manpower. Cambridge (Mass.).

Freeman, R.B. (1989), Labour Markets in Action. New York.

Hart, A.G. (1937), 'Anticipations, Business Planning, and the Cycle'. Quarterly Journal of Economics 51, pp.273-297.

Kaldor, N. (1934), 'A Classificatory Note on the Determinateness of equilibrium'. Review of Economic Studies 1, pp. 122-136.

Siow, A. (1984), "Occupational Choice under Uncertainty'. Econometrica 52, pp. 631-645.

Smyth, D.J. (1973), 'Effect of Public Price Forecast on Market Price Variation: A Stochastic Cobweb Example'. American Journal of Agricultural Economics 56, pp. 706-716.

Spear, S.E. (1989), 'Learning Rational Expectations under Computability Constraints'. Econometrica 57, pp. 889-910.

Turnovski, S.J. (1978), 'Stabilization Rules and the Benefits from Price Stabilization'. Journal of Public Economics 12, pp. 301-327.

Zarkin, G.A. (1983), 'Cobweb versus Rational Expectations Models'. Economics Letters 13, pp. 87-95.

Zarkin, G.A. (1985), 'Occupational Choice: An Application to the Market for Public School Teachers'. Quarterly Journal of Economics 100, pp. 409-446. 